\title{
A GEOGRAFIA JURÍDICA DE JOSÉ NICOLAU DOS SANTOS: DEBATES COM A MODERNA GEOGRAFIA DO DIREITO
}

\author{
THE JURIDICAL GEOGRAPHY OF JOSÉ NICOLAU DOS SANTOS: \\ DEBATES WITH THE MODERN GEOGRAPHY OF LAW \\ LA GÉOGRAPHIE JURIDIQUE DE JOSÉ NICOLAU DOS SANTOS: \\ DEBÁTS AVEC LA MODERNE GÉOGRAPHIE DU DROIT \\ Jonas Dias de Souza - Universidade de São Paulo - São Paulo - São Paulo - Brasil \\ jdsgeo10@yahoo.com
}

\begin{abstract}
Resumo
José Nicolau dos Santos foi professor da Universidade Federal do Paraná desenvolvendo trabalhos, nos anos de 1950, sobre a relação entre Geografia e Direito, denominada Geografia Jurídica. Contudo, pouco se conhece dos trabalhos de Santos. 0 objetivo deste artigo é recuperar as principais ideias do autor, estabelecendo um diálogo com as atuais pesquisas sobre o tema. Apresentamos a justificativa e os objetivos da Geografia Jurídica, os autores e as obras que trabalham a relação entre Geografia e Direito elencados por Santos, o conceito de temisfera e, por fim, suas considerações sobre direito comparado e migrações do direito.
\end{abstract}

Palavras-chave: José Nicolau dos Santos, Geografia Jurídica, Geografia do Direito.

\section{Abstract}

José Nicolau dos Santos was University of Paraná teacher, developing studies, in 1950', about the relationship between Geography and Law, denominated Juridical Geography. Nevertheless, his work is not well known. This paper aims recover author main ideas and establish a debate with current researches. Firstly, it is presented Juridical Geography justification and objectives and the works about the theme enumerated by Santos, the concept of temisfera and, lastly, his consideration about comparative law and law migrations.

Key words: José Nicolau dos Santos, Juridical Geography, Geography of Law.

\section{Resumé}

José Nicolau dos Santos a été professeur de la Université du Paraná, et il a étudié, dans les années 1950, la relation avec Géographie et Droit, appelé Géographie Juridique. Néanmoins, on connais peu de son travail. Cette article a le objectif de récupérer les idées du auteur et discuter avec la moderne Géographie du Droit. Tout d'abord, on présente la justification et les objectifs de la Géographie Juridique et les travaille qui ont discutée cette sujet, le concept de temisfera et, à la fin, ses considération sur droit comparé et migration du droit.

Mots-clés: José Nicolau dos Santos, Géographie Juridique, Géographie du Droit.

\section{Introdução}

José Nicolau dos Santos foi professor catedrático da Faculdade de Direito, da Faculdade de Filosofia e da Faculdade de Ciências Econômicas da Universidade Federal do Paraná, ocupando o cargo de Reitor pela mesma instituição entre 1964 e 1967. Dentre os estudos desenvolvidos pelo professor, na área de estatística, de ciências políticas e na área de te- 
oria geral do estado, encontram-se trabalhos sobre a relação da Geografia e do Direito, os quais, contudo, são pouco conhecidos e discutidos pelos acadêmicos de geografia.

Este artigo tem o propósito, pois, de recuperar as principais ideias de Santos com o fim de, primeiro, torná-lo mais conhecido no meio acadêmico e, segundo, fazer um debate com as teorias mais atuais da Geografia do Direito.

A pesquisa baseou-se na revisão e sistematização dos seguintes trabalhos do autor: Geografia Humana e Teoria Geral do Estado, memorial apresentado, em 1951, como defesa do professor para demonstrar "nosso direito líquido e certo" de permanecer como titular nas cadeiras de Geografia Humana e Teoria Geral do Estado simultaneamente; Fundamentos da Geografia Jurídica, de 1954, em que Nicolau dos Santos expõe de maneira mais detalhada os objetivos e fundamentos da geografia jurídica e a interpretação dos fatos geojurídicos; Direito Comparado e Geografia Jurídica, de 1955, texto no qual o autor tenta aproximar os métodos de pesquisa do Direito Comparado das "proveitosas contribuições da metodologia antropogeográfica”; e, por último, As Migrações do Direito, de 1956, um estudo sobre as "migrações geográficas das leis".

Neste artigo, apresentamos inicialmente a discussão sobre a denominação e os objetivos da Geografia Jurídica para, em seguida, elencar os autores mencionados por Nicolau dos Santos que trabalham a relação entre Geografia e Direito (recuperação importante dada a falta de referências na área). São recuperados também o conceito de temisfera e as discussões do autor sobre direito comparado e migrações do direito.

Da denominação e objetivos da Geografia Jurídica

“Torna-se mais específico e apropriado o título Geografia do Direito ou o de Geografia Jurídica?"questiona-se José Nicolau dos Santos (1954) logo nas primeiras páginas de Fundamentos da Geografia Jurídica.

O problema da denominação desse sub-ramo da Geografia é uma questão até hoje não resolvida pelos autores que discutem a relação da Geografia com o Direito. Com efeito, geodireito, estudos geolegais ou geojurídicos, geografia do direito, geojurisprudência e geografia jurídica, geografia legal e direito geográfico são termos que se alternam nas obras de autores que tratam do assunto (Souza, 2013). 
Santos, no entanto, resolve a dúvida sobre a nomenclatura "com apelo aos filólogos”, mais especificamente, por uma analogia com a Geografia Linguística e a Geografia das Línguas. Logo, assim como a Geografia Linguística é "a reconstituição histórica das palavras e flexões e de suas transformações, determinadas por influências diversas, inclusive ‘das condições geográficas do meio, com o qual o homem é solidário’”, a Geografia Jurídica é "uma reconstituição histórica das instituições jurídicas, apreciando a sua origem e evolução no tempo, em consequência dos fatores geográficos sinergéticos que condicionam aquelas instituições". O autor, em síntese, também afirma que "a Geografia Jurídica buscará o germe da transformação do Direito através dos meios geográficos sucessivos" (Santos, 1954, p. 183-184; grifos no original).

A Geografia do Direito, conforme preleciona o professor, estuda "a distribuição atual das leis, a diversidade ou similitude das codificações, o império ou expansão dos institutos jurídicos, a intercessão e o conflito das legislações no espaço, determinados sobretudo pelas influências geográficas" (Santos, 1954, p. 182-183; grifos no original), estando em conformidade com seu congênere Geografia das Línguas, a qual estuda a distribuição das línguas faladas.

Assim, enquanto a Geografia do Direito está precipuamente preocupada com o princípio da extensão dos fenômenos, considera Santos, a Geografia Jurídica "primária e essencialmente deve nortear-se pelo princípio da correlação (ou conexidade) dos fenômenos”. A finalidade dessa última é, então, "interpretar todas as manifestações do fenômeno jurídico [...] em suas relações permanentes com o meio antropogeográfico, que é o condicionamento material da sociedade" (Santos, 1954, p. 191-192).

Portanto, ficam delimitadas, para o autor, as áreas de competência da Geografia Jurídica e da Geografia do Direito.

\section{Encontros e desencontros nos estudos da relação Geografia e Direito}

Nos atuais estudos da relação entre Geografia e Direito, ressentem-se frequentemente os autores da ausência de pesquisas e textos sobre o tema (Blomley, 1994; Antas Junior, 2005; Forest, 2009). Mesmo José Nicolau dos Santos avalia:

Mas evidenciemos desde já que a teoria sociológica do Estado, como também a concepção fenomenológica do Direito mantém com a Ge- 
ografia Humana correlações científicas tão aprofundadas e interdependências conceituais tão indissolúveis que, tudo quando nos pode causar espanto e lástima é serem tão minguadas, tão esparsas e vacilantes as pesquisas dos modernos tratadistas nessa farta messe da geojurisprudência. (Santos, 1954, p. 177)

No decorrer dos seus trabalhos, Santos apresenta, então, uma série de obras e autores que, em menor ou maior grau, cuidam da relação entre Geografia e Direito. Em virtude da falta de referências de textos e de autores na área, vamos transcrever as referências mencionadas por Santos. ${ }^{1}$

Merece registro do autor, apesar de que "só incidentalmente e em rápidas observações aludem ao tema geojurídico”, a obra do geógrafo americano Roberto Strausz-Hupé - Geopolítica: la lucha por el espacio y el poder (México: Ed. Hermes, 1945) - e a monografia de Edmundo A. Walsh - Geopolítica y moral internacional (compõe a coletânea de Weigert e Stefanson: Política y poder en un mundo mas chico. Buenos Aires: Ed. Atlântida, 1944).

O artigo do professor Réné David (1948), La Geographie et le Droit, ${ }^{2}$ também é citado por Santos, pois chama "a atenção dos antropogeógrafos para uma correlação necessária e visível entre o meio telúrico e o pensamento jurídico" (Santos, 1954, p. 181). Vale lembrar que Antas Junior (2005), mais recentemente, também menciona outro artigo de David René, Géograhie Juridique, ${ }^{3}$ sobre a interação entre a Geografia e o Direito.

Cabe menção especial de Nicolau dos Santos à obra do geopolítico americano Derwent Whittlesey, Geografia política (México: Ed. Fondo de Cultura, 1948), por "haver pronunciado com maior desembaraço e nitidez os conceitos de um intenso determinismo geográfico modelando, impulsionando e transformando a legislação dos povos" (Santos, 1954, p. 181).

O nome de Marc Dessertaux é igualmente citado, mas Santos não diz a qual trabalho se refere. Provavelmente o autor esteja aludindo ao artigo Droit comparé et géographie humaine publicado nos Annales de Géographie, em 1947.

Por último, depois de mencionar as breves considerações que Max Sorre faz sobre La Geographie du Droit, trabalho já conhecido dos atuais pesquisadores, José Nicolau dos Santos cita a monografia de André Siegfried, Géographie Electoralle de l'Árdéche sous la III République (Paris: Cahier des Sciences Politiques, 1949), e a de M. François Goguel, Géographie des Elections Françaises de 1870 a 1951 (Paris: Cahiers de la Fondation Nationale des Sciences Politiques, 1951). 
A par desses trabalhos geográficos que "[correm] de encontro ao Direito, para um entrelaçamento mais íntimo e por certo mais profícuo", Santos menciona e utiliza uma série de obras de Teoria Geral do Estado e da Geografia Humana para fundamentar sua Geografia Jurídica. Para o professor do Paraná, entre a Geografia Humana e a Teoria Geral do Estado, "existem mútuas referências, laços de afinidade quanto às suas matérias, interdependência dos seus conceitos, intercomunicação de suas doutrinas" (Santos, 1951, p. 16); chega o autor a afirmar que "os mesmos autores e as mesmas obras históricas que fizeram nascer a Teoria Geral do Estado também deram origem à Geografia Humana" (p. 32). "Ao contrário do que os geógrafos costumam afirmar, nem a Escola Determinista, nem a Possibilista são criações geográficas, mas sim escolas jurídicas, não sendo possível omitir neste assunto os nomes de Montesquieu e de Bluntschli, pelo menos," assevera Santos (1954, p. 211).

Assim considerado, José Nicolau dos Santos elenca uma série de autores clássicos que fundamentam sua discussão sobre a relação Geografia/Direito, nomeadamente, sua ideia da Geografia Humana e Teoria Geral do Estado como "ciências correlatas". Aristóteles na Política; Platão nas Leis; São Tomás de Aquino com O governo dos príncipes; Jean Bodin em Os seis livros da república; Montesquieu no Espírito das leis e tratadistas mais modernos, como Johann Kaspar Bluntschli, R. Kranenburg e Darcy Azambuja, que tanto constituem "as pedras angulares e eternas" da Teoria Geral do Estado quanto são "igualmente nomeados e cultuados por todos os antropogeógrafos como pedras representativas dos alicerces sólidos e vetustos em que se apoia a moderna Geografia Humana” (Santos, 1951, p. 32-33).

Contra possíveis argumentos que afirmem "que as obras de Aristóteles, Platão, Bodin, Montesquieu eram obras sem plano determinado, sem objetivo específico, misturando ecleticamente os mais distanciados assuntos" (Santos, 1951, p. 53), este autor apoia suas assertivas sob argumentos de autoridade como Lucien Febvre, Amorim Girão, Hermann Heller, Hans Weigert para, posteriormente, mostrar a referência cruzada, "mútuas que se fazem os antropogeógrafos e os teoristas do Estado" (Santos, 1951, p. 44 e ss). 


\section{A temisfera}

Do conceito de noosfera enunciado por Pierre Chardin, na primeira metade do século XX, José Nicolau dos Santos deriva a ideia de temisfera ou esfera do pensamento jurídico. Dentro dessa esfera do pensamento, dessa esfera em que opera a razão humana,

nesse envelope, nessa capa psíquica e imponderável de todas as camadas físicas e biológicas (biosfera), que integram a morfologia planetária, pode situar-se a marca mais constante e imperiosa da mente humana que é o Direito, constituindo assim uma esfera nova e específica, a qual chamaremos temisfera, ou seja, a esfera legal, o envólucro jurídico norteador e dominante das demais atividades geossociais. (Santos, 1956, p. 308)

A esfera do pensamento jurídico, por um lado, assim como o "espírito religioso", materializa na face da Terra "tribunais e parlamentos, aduanas e prefeituras, edificações onde as leis são elaboradas ou aplicadas, e que revelam sempre uma fisionomia adequada às funções que exercem" (Santos, 1954, p. 194). Mas, por outro lado, pondera o autor,

julgamos não ser a materialização do Direito em edifícios que assinale melhor a marcha do pensamento jurídico sobre a fisionomia do nosso planeta. Muito mais do que isso, a Terra está dividida em compartimentos estanques, fragmentada em nacionalidades independentes, repartida em Estados politicamente soberanos [...]. As fronteiras são como extensas cercas configurando territórios e, dentro delas, as leis e os costumes juridicamente aceitos diferenciam as atividades humanas, modelam e diversificam a mentalidade dos povos, criando além de uma simples 'paisagem humanizada' uma verdadeira e nítida paisagem espiritual, típica de cada nacionalidade. (Santos, 1954, p. 195; grifos no original)

Justamente por estar fragmentada em nacionalidades independentes, por operar em superfícies de domínio estatal delimitadas, a esfera jurídica, ou temisfera, se presta melhor a ser cartografada. Assim, Santos afirma:

A validade espacial das jurisprudências estatais, a extensão e o domínio de cada soberania política decorrem sempre dentro de perímetros geográficos rigorosos e previstos. Por consequência, da noosfera ou da psicosfera, a manifestação mais importante, com possibilidade da mais rigorosa representação cartográfica é precisamente a esfera imperativa do Direito. (Santos, 1954, p. 198) 
Acerca da ideia de temisfera desenvolvida por Nicolau dos Santos, é válido notar alguns pontos de discussão que se estabelecem com os atuais autores da Geografia do Direito.

Por exemplo, a conexidade entre os fenômenos jurídicos e o meio antropogeográfico é deveras importante, para Nicolau dos Santos, porquanto "assuntos comuns e entrelaçados da Geografia com o Direito só pela conjunção dos conceitos geográficos e jurídicos podem exprimir algum sentido" (Santos, 1954, p. 188). Estado, fronteira e mar territorial, por exemplo, "não podem ser pensados, nem conceituados senão nos termos dessa íntima correlação jurídica - antropogeográfica”, assevera o professor da Universidade do Paraná (Santos, 1951, p. 54-55).

Nesse sentido, a percepção de José Nicolau dos Santos sobre a íntima correlação jurídica - antropogeográfica adianta, devemos notar, o sentido do conceito splice construído por Delaney (2003) e Blomley, Delaney e Ford (2001) mais recentemente. De fato, 50 anos depois dos escritos de Santos, sublinham os modernos autores da Geografia do Direito que "o legal e o espacial são, de maneiras significantes, aspectos um do outro"; leis e espaço se "constituem reciprocamente" (2001, p. xviii). A lei possui um aspecto espacial indispensável, uma concretude geográfica que lhe dá materialidade inafastável, sem a qual a lei perde efetividade (Garcier, 2009).

Santos argumenta no mesmo sentido quando cita Maurício Halbwachs sobre as instituições criadas pelo Direito: "As instituições não são simples ideias: devem ser tomadas ao nível do solo, inteiramente carregadas de matéria, matéria humana e matéria inerte, organismo em carne e osso, edifícios, casas, lugares, aspectos do espaço" (Santos, 1956, p. 194; grifos no original).

Outro diálogo possível é com Rutherford Platt (2004) por assumir que as leis são agentes sutis, mas onipresentes na modelação das formas urbanas e da paisagem rural, mesma ideia aludida por Santos numa rápida passagem, ao afirmar que "a fonte de produção e de consumo, os roteiros de comunicações comerciais, enfim a generalidade dos fatos geoeconômicos, assumem uma feição típica de lugar para lugar, marcadas pela ação jurídica invisível, mas imperiosa” (Santos, 1954, p. 194). Platt, contudo, avança na ideia discernindo entre direito público e direito privado e pondera que, na esfera legal, ambos são contrabalanceados na definição de direitos e de legitimidades, chegando por fim ao que ele denomina de legal landscape, isto é, paisagem legal (Platt, 2004, p. 19). 
Em outra passagem, mesmo de maneira rápida e pouco aprofundada, Santos afirma que "também como a Religião, e muito mais de que ela, o Direito introduz nas economias regionais, agrárias ou industriais, um complexo de normas fiscais e administrativas que o meio antropogeográfico sugere". Um pouco mais à frente, ele complementa a informação, afirmando que "não há um só núcleo associativo humano, do mais simples ao mais complexo onde o Direito não penetre para gizar a sua forma externa, a sua estrutura interna, as suas funções orgânicas: ubi societas ibi jus [onde está a sociedade está o Direito]" (1954, p. 194; grifos nossos). O meio antropogeográfico sugere um complexo de normas fiscais e administrativas, gizar suas funções orgânicas não é, em certo sentido, o mesmo significado de interação entre objetos e ações trabalhadas por Antas Junior (2005)? Isto é, não estariam estes dois autores indo na mesma direção quando este autor afirma que "há a presença de densidades normativas variadas, conforme a quantidade e a qualidade com que esses dois elementos [objetos e ações] distribuem-se pela superfície terrestre" (Antas Junior, 2005, p. 52)?

\section{Direito Comparado, Migrações do Direito e Geografia Jurídica}

A temisfera, essa "atmosfera jurídica condicionante da humanidade é certamente una”, afirma Santos. O autor continua, mais à frente, ponderando,

mas esta se diferencia em climas mais quentes ou frios, mais secos ou úmidos, em virtude de fatores mesológicos locais [...]. A Geografia Jurídica não pode, portanto, deixar de concluir que a Unidade do Direito existe, mas em suas mais genéricas manifestações de princípios, como expressão de um Direito Natural [...]. O Direito Positivo, porém, contingente, nascido das necessidades sociais, criado pelo Estado para atender a um mínimo de exigências éticas reguladoras das multiformes relações interindividuais ou intergrupais, esse Direito que se consubstanciou na forma de usos, costumes e afinal da lei escrita e sancionada é, por essência, variável de povo para povo, de região para região. Constitui os climas morais, de Taine, diversificados por influências várias, inclusive dos fatores telúricos, dentro da unidade geral da Temisfera. (Santos, 1955, p. 369; grifos no original)

Nesse sentido, enquanto o Direito Comparado tem o "escopo de empreender a unificação do Direito, avalia Santos, a Geografia Jurídica, 
até certo ponto, demonstra que as legislações surgidas naturalmente dos meios geográficos típicos e diferenciados jamais terão a oportunidade de serem artificialmente uniformizadas" (Santos, 1955, p. 350).

No final, as duas disciplinas se complementam, mesmo que, à primeira vista, elas se invalidam. Por um lado, a Geografia Jurídica necessita do auxílio do Direito Comparado "para alicerçar conclusões sobre a comparação de leis semelhantes ou dissemelhantes que dominam a face da Terra"; por outro, autores do Direito Comparado (Cândido de Oliveira, Marc Ancel, Ilmar Penna Marinho, afirma Nicolau dos Santos) não deixam de usar "o método geográfico para a interpretação das diferenças ou analogias sensíveis do Direito entre os diversos povos" (Santos, 1955, p. 355).

Para Santos, afinal, a Geografia Jurídica indicaria ao Direito Comparado até que ponto as diferentes instituições jurídicas dos povos são semelhantes diante das condições geográficas idênticas ou diferenciadas.

Se a temisfera constitui uma unidade que se diferencia nos territórios nacionais, conforme as particularidades antropogeográficas de cada povo, há de se considerar também, na "gênese e metamorfose do fenômeno jurídico”, a evolução do Direito no tempo e o seu transporte no espaço:

No mundo em que vivemos, o movimento - não a rigidez e a imobilidade - constitui a lei geral. Também a temisfera, parte integrante da psicosfera planetária, como esta, move-se e evolui constantemente. O Direito, suas instituições, suas leis ou seus princípios, transformam-se no tempo, que é a História, e transmigram ou transportam-se no espaço, que é a Geografia. Não seria incompreensível ou absurdo que falássemos em uma migração geográfica das leis, como não é incomum ou surpreendente aludirmos a uma evolução histórica dessas mesmas leis. (Santos, 1956, p. 308)

Quer dizer, não bastam apenas as razões telúricas na origem das instituições jurídicas; para explicá-las, interessa igualmente o movimento do Direito no espaço.

Dentre as leis que "transmigram no espaço", são as leis que emigram "e que definitivamente se incrustam na legislação de outros povos" as que importam para Nicolau dos Santos, visto que "elas definem a equivalência das necessidades geográficas, econômicas e sociais a que foram chamadas a tutelar em circunscrições políticas diversas” (Santos, 1956, p. 312; grifos no original).

Ambientes geográficos semelhantes que demandariam necessidades semelhantes levam Santos a crer "que o fator mais ponderável da 
imigração de uma lei seja quase sempre o geográfico”, justificando a importação de leis análogas de outros povos, portanto, avalia Santos (1956, p. 313; grifos no original).

Há, contudo, não se esquece o autor, da capitulação de soberanias de certos Estados quando o movimento de migração das leis não é espontâneo. E ele adverte que "coloquemos desde já em realce que a inspiração do regime capitular decorreu, sem dúvida, da necessidade do comércio internacional, que por sua vez é um inconteste fato antropogeográfico" (Santos, 1956, p. 317; grifos no original).

A Geografia Jurídica, enfim, fornece parâmetros teóricos e metodológicos para se entender a gênese e a transformação do Direito. Para Santos, a temisfera vincula-se de maneira intrínseca com o meio telúrico, evidenciada nos trabalhos de Direito Comparado e na explicação das migrações do Direito no espaço.

\section{Considerações finais}

De todo o exposto, quais ensinamentos podemos apreender de José Nicolau dos Santos e quais contribuições podemos deter para as atuais discussões da Geografia do Direito?

Em comparação com os hodiernos debates da Geografia do Direito, Santos mostra certa atualidade ao reconhecer a "feição típica de lugar para lugar, marcada pela ação jurídica invisível, mas imperiosa” e, mais importante ainda, ao sublinhar o aspecto espacial, a dimensão geográfica inerente à lei. De fato, a conformação jurídica da feição dos espaços e das paisagens é o momento mesmo de realização da natureza antropogeográfica do Direito - para empregarmos o termo usado por Santos.

Outrossim, além das indicações bibliográficas trazidas pelo autor, as quais suprem certa carência de referências na área, vale destacar também, nos seus fundamentos da Geografia Jurídica, o conceito de temisfera como "o envólucro jurídico norteador e dominante das demais atividades geossociais”. Um maior desenvolvimento do conceito elucidaria aspectos importantes da relação da sociedade com a natureza, ampliaria o entendimento da diferenciação do direito no seara do Direito Comparado e levaria a críticas quanto à migração arbitrária das leis entre "condições telúricas" diferenciadas. 
O Direito Ambiental, por exemplo, apresenta o objetivo de regulamentar a relação do homem com o meio ambiente (Machado, 2010; Milaré, 2013). O que da relação homem/natureza esse Direito revela? Qual o sentido da diferenciação do Direito Ambiental nos diferentes Estados e quais os problemas apresentam uma importação indiscriminada de leis ambientais forjadas em condições geográficas específicas?

Com base nos trabalhos de José Nicolau dos Santos, um debate possível, por fim, refere-se à gênese e à transformação geográfica do Direito - discussão de certa forma negligenciada atualmente. Isto é, se os mais recentes autores de Geografia do Direito reconhecem a dimensão espacial da lei, mostrando sua manipulação segundo os interesses dominantes, poucos discutem a sua origem na essência geográfica. Nesse sentido, Santos, embora se fundamente em argumentos marcados por um viés determinista, repõe uma questão de vital interesse para se aprofundar o entendimento da relação entre a Geografia e o Direito.

\section{Notas}

1. São transcritas as obras, conforme registradas por José Nicolau dos Santos; o local, a editora e o ano da edição são indicados entre parênteses para uma posterior consulta.

2. O artigo de Réné David se encontra na La Revue de Géographie Humaine et Ethnologie. Paris, $\mathrm{n}^{\mathrm{o}}$ 1, janvier-mars, 1948. Como Santos só cita o nome do artigo, a referência completa foi retirada do trabalho de André Allix (1949).

3. Conferir René David (1996).

\section{Referências}

ALLIX, André. Deux nouvelles revues françaises de géographie. Revue de Géographie Jointe au Bulletin de la Société de Géographie de Lyon et de la Région Lyonnaise, v. 24, n. 1, p. 72-75, 1949. Disponível em: <http://www.persee.fr/ web/revues/home/prescript/article/geoca_1164-6284_1949_num_24_1_6619 >. Acesso em: 14 jan. 2014.

ANTAS JUNIOR, Ricardo Mendes. Território e regulação: espaço geográfico, fonte material e não formal do direito. São Paulo: Associação Editorial Humanitas: Fapesp, 2005.

BLOMLEY, N. Law, space and the geographies of power. New York: The Guilford Press, 1994.

BLOMLEY, N.; DELANEY, D. FORD, R. The legal geographies reader: law, power and space. Oxford: Blackwell Publishers, 2001. 
DAVID, René. Géographie juridique. In: Journaux, Deffontainesm Delammerre (Org.). Géographie Générale. Paris: Gallimard, 1996. p. 1738-1748.

DELANEY, David. Beyond the word: law as a thing of this world. In: HOLDER, J. HARRISON, Carolyn. Law and geography: current legal issues, v. 5. New York: Oxford University Press, 2003.

FOREST, Patric. Géographie du droit: épistémologie, développement et perspectives. Canadá : Les Presses de l’Université Laval, 2009.

GARCIER, R. Le droit et la fabrique de l'espace : aperçus méthodologiques sur l'usage des sources juridiques em géographie. In: FOREST, P. (Org.). Géographie du droit : épistémologie, développement et perspectives. Canadá : Les Presses de l’Université Laval, 2009. p. 70-91.

MACHADO, Paulo Affonso Leme. Direito ambiental brasileiro. 18. ed. São Paulo: Malheiros Editores, 2010.

MILARÉ, Édis. Direito do ambiente. 8. ed. rev. atual. e ampl. São Paulo: Revista dos Tribunais, 2013.

PLATT, Rutherford. Land use and society: geography, law, and public policy. Revised Edition. Washington: Island Press, 2004.

SANTOS, José Nicolau dos. Geografia humana e teoria geral do estado: ciências correlatas. Curitiba: Guaíra, 1951.

. Fundamentos da geografia jurídica. Revista da Faculdade de Direito da UFPR, Paraná, v. 2, p. 174-261, 1954.

. Direito comparado e geografia jurídica. Revista da Faculdade de Direito $\bar{d} \bar{a} \bar{U} \bar{F} \bar{P} R$, Paraná, v. 3, p. 348-371, 1955.

. As migrações do direito. Revista da Faculdade de Direito da UFPR, Paraná, v. 4, p. 307-322, 1956.

SOUZA, Jonas Dias de. A relação entre a geografia e o direito: notas bibliográficas. Revista do Departamento de Geografia - USP (Online), São Paulo, v. 25, p. 263285, 2013.

Jonas Dias de Souza - Graduado, Mestre e Doutorando em Geografia pela Universidade de São Paulo.

Recebido para publicação em 8 de março de 2014 Aceito para publicação em 30 de abril de 2014 